\title{
Radioisotope Heater Unit-Based Stirling Power Convertor Development at NASA Glenn Research Center
}

\author{
Scott D. Wilson ${ }^{1}$, Steven M. Geng ${ }^{2}$ \\ NASA Glenn Research Center, Cleveland, Ohio, 44135 \\ Lawrence B. Penswick ${ }^{3}$ \\ Consultant, 121 Carefree Dr, Stevenson WA 98648 \\ Paul Schmitz ${ }^{4}$ \\ Vantage Partners, LLC., 3000 Aerospace Parkway, Brook Park OH, 44142
}

\begin{abstract}
Stirling Radioisotope Power Systems (RPS) are being developed as an option to provide power on future space science missions where robotic spacecraft will orbit, flyby, land or rove. A variety of mission concepts have been studied by NASA and the U. S. Department of Energy that would utilize RPS for landers, probes, and rovers and only require milliwatts to tens of watts of power. These missions would contain science measuring instruments that could be distributed across planetary surfaces or near objects of interest where solar is flux insufficient for using solar cells. A low power Stirling convertor is being developed at NASA Glenn Research Center (GRC) to provide an RPS option for future low power applications. Initial concepts convert heat available from several Radioisotope Heater Units to electrical power for spacecraft instruments and communication. Initial development activity includes defining and evaluating a variety of Stirling configurations and selecting one for detailed design, research of advanced manufacturing methods that could simplify fabrication, evaluating thermal interfaces, characterizing components and subassemblies to validate design codes, and preparing for an upcoming proof of concept demonstration in a laboratory environment.
\end{abstract}

\section{Nomenclature}

$\begin{array}{ll}\text { AM } & =\text { Additive Manufacturing } \\ \text { ASRG } & =\text { Advanced Stirling Radioisotope Generator } \\ \text { DOE } & =\text { Department of Energy } \\ \text { GPHS } & =\text { General Purpose Heat Source } \\ \text { GRC } & =\text { Glenn Research Center } \\ \text { MLI } & =\text { Multi-Layer Insulation } \\ \text { MMRTG } & =\text { Multi-Mission Radioisotope Thermoelectric Generator } \\ \text { RHU } & =\text { Radioisotope Heater Unit } \\ \text { RPS } & =\text { Radioisotope Power Systems } \\ \text { SCTDP } & =\text { Stirling Cycle Technology Development Project } \\ \text { SRG-110 } & =\text { Stirling Radioisotope Generator - 110 Watts } \\ \text { TEC } & =\text { thermoelectric couple }\end{array}$

\section{Small Radioisotope Power Systems and Applications}

tirling Radioisotope Power Systems (RPS) are being developed by NASA's RPS Program in collaboration with $\checkmark$ the U.S. Department of Energy (DOE). SRGs could provide power to future space science missions where robotic spacecraft will orbit, flyby, land or rove. The Stirling Cycle Technology Development (SCTD) Project is funded by

\footnotetext{
${ }^{1}$ Mechanical Engineer, Thermal Energy Conversion Branch, 21000 Brookpark Rd/Mail Stop 301-2, AIAA Member.

${ }^{2}$ Mechanical Engineer, Thermal Energy Conversion Branch, 21000 Brookpark Rd/Mail Stop 301-2, AIAA Member.

${ }^{3}$ Engineering Consultant, 121 Carefree Dr, Stevenson WA 98648, AIAA Non-Member

${ }^{4}$ Engineer, Vantage Partners, LLC., 3000 Aerospace Parkway, Brook Park OH, 44142AIAA Non-Member.
} 
the RPS Program to develop Stirling-based subsystems, including maturation of convertor and controller technologies for future RPS missions. The SCTD Project also performs research to develop less mature technologies with a wide variety of objectives, including increasing temperature capability to enable new environments, improving system reliability or fault tolerance, reducing mass or size, and developing advanced concepts that inform decision making or are mission enabling. Future science missions will need more efficient conversion systems to provide power for future Discovery and New Frontiers spacecraft. NASA Spacecraft have successfully used Radioisotope Thermoelectric Generators (RTGs) since 1961 to enable scientific exploration of the Moon, the Sun, Venus, Mars, Jupiter, Saturn, Uranus, Neptune, and Pluto. These RTGs demonstrated high reliability but relatively low efficiency. Dynamic power conversion technologies, like Stirling convertors, are being developed to increase system efficiency for future missions to $20-25 \%$.

In addition to 100-watt class power systems that would normally use two GHPS Step-2 modules, a variety of low power mission concepts have been studied by NASA and the U. S. Department of Energy that would utilize RPS for micro landers, probes, and rovers and only require milliwatts to tens of watts of power. ${ }^{1}$ Missions could include a network of geophysical stations that contain science measuring instruments and are distributed across planetary surfaces or near objects of interest where solar flux is insufficient for using solar cells. Some missions would utilize a single GPHS Step-2 module while others were proposed to use single or multiple Radioisotope Heater Units (RHUs) to provide heat to the conversion technology.

Small RPS concepts that would use the available heat from one or more RHU include solid state thermoelectric couple (TEC) convertors and dynamic convertors, like Stirling. Reference 1 documented a total of 14 potential missions that would be enabled by a RHU-based power systems. The vast majority of systems designed for use with one or more RHU have been based on TECs. RTGs are solid-state conversion technologies that have reliably provided 26 spacecraft with electrical power since 1961. These power systems have demonstrated efficiencies of around $6 \%$ for designs that use the GPHS Step-2 modules as a heat source and between 2-4\% efficiency for milliwatt designs that would use the RHU as a heat source. There have been several RHU-based thermoelectric efforts, including NASA ARC, Hi-Z, JPL/Swales, and the Russian BIAPOS. Most have been demonstrated in a laboratory vacuum environment, converting $1 \mathrm{Wt}$ of thermal energy available from a RHU to $40 \mathrm{mWe}$ of electrical power output. The MASER study used six $40 \mathrm{mWe}$ conversion systems to provide a Mars lander weather station with $240 \mathrm{mWe}$ of electrical power. ${ }^{2}$ Relying on trickle charging and stored energy to perform basic functions, MASER used duty cycling to support data collection from several instruments and data transmission from an antenna. However, duty cycling could reduce the data collection frequency, making it more difficult to discriminate between different weather phenomena, like wind storms and seismic events.

One way to improve data rates and communications, and in turn improve data quality is to provide more power to the end user. However, coupling multiple RHUs together and achieving an efficient insulation package can be challenging due to the shape factor of the combined RHUs. As more RHUs are added in either the length or width dimensions, an effective insulation package could exceed some practical size limitation or the RHU arrangement could make thermal management more challenging. Dynamic power systems are known for high efficiency, which could be beneficial when fuel is scarce or when an elevated heat signature is undesirable. In the case of very low power systems, high efficiency could enable equal power for less fuel or higher power for equal fuel, both of which could benefit the overall size of a power system when compared to less efficient conversion technologies. A low power Stirling convertor is being investigated to provide RPS micro spacecraft with between 0.1-1.0 watt of electrical power. An initial concept would convert heat available from eight RHUs to 1-watt of electrical power for spacecraft instruments and communication. Providing the spacecraft with more power could decrease reliance on duty cycling to perform basic functions and increase the frequency and quality of science data.

\section{1-Watt Mini Stirling Convertor}

NASA GRC is developing a 1-watt mini Stirling convertor for low power RPS applications. Development of the low power Stirling convertor includes gaining an understanding of all interrelated components within a system. Each component is related to one or more of the other components within the system and could have critical dependencies, including mechanical, thermal, and electrical interfaces. The interfaces of interest are between a spacecraft sensor to the environment the sensor is intended to survey. Table I shows each component and the dependency on a connected component. Components include a spacecraft structure, mounting to the insulation package, the heat source being insulated, the engine interface to the heat source, the alternator connected to the engine, the controller connected to the alternator, and the power system connected to the controller that provides sensors with usable power. The dependencies were identified in an attempt to understand influences on all interconnected parts. To simplify the initial effort, only deep space and Mars surface environmental temperatures were considered. The number of RHU heat 
sources was selected based on packaging options for heater assemblies, containing between 3-8 RHUs. Packing RHUs in a side-by-side fashion or flat arrangement increased the overall insulation package diameter and made it necessary to reroute heat back toward the hot end of the Stirling. Stacking RHUs lengthwise also has its disadvantages as the length increases, however, the desire to maximize convertor power output and minimize overall diameter led to the decision to select a total of 8x RHUs, essentially two RHUs long and four RHUs arranged in a pattern around the hot end of the Stirling convertor.

Table I shows dependencies and other considerations for each component that could affect functionality of the system. For example, the insulation dependencies include structural mounting loads and environmental temperatures while the engine is dependent on the insulation efficiency to enable a sufficient hot end engine temperature. The insulation considerations include robustness for surviving external loads, yield and repeatability, overall thermal efficiency, and overall size.

Table I. High Level Design Considerations for 1-Watt Stirling

\begin{tabular}{|c|c|c|c|}
\hline Component & Dependencies & Considerations & Goals \\
\hline \multirow{2}{*}{$\begin{array}{l}\text { Spacecraft } \\
\text { mounting }\end{array}$} & Environment & \multirow{2}{*}{$\begin{array}{l}\text { 1-vacuum } \\
\text { 2-temperatures } \\
\text { 3-compatibility }\end{array}$} & \multirow{2}{*}{$\begin{array}{l}\text { 1-assumed vacuum testing } \\
\text { 2-assumed: 25, 0, -50,-270 } \\
\text { 3-address later }\end{array}$} \\
\hline & Structural interfaces & & \\
\hline \multirow{2}{*}{ Insulation } & Temperatures, loads & \multirow{2}{*}{$\begin{array}{l}\text { 1-robustness } \\
\text { 2-manufactureability } \\
\text { 3-efficiency } \\
\text { 4-size }\end{array}$} & \multirow{2}{*}{$\begin{array}{l}\text { 1-robust for handling and life cycle loads } \\
\text { 2-repeatable and able to model } \\
\text { 3-engineered effective thermal conductivity } \\
\text { 4-fits inside } 10 \mathrm{~cm} \text { diameter }\end{array}$} \\
\hline & Thermal efficiency & & \\
\hline \multirow{2}{*}{$\begin{array}{l}\text { Heat Source } \\
\text { (8-Wt input) }\end{array}$} & Heat lost to insulation & \multirow{2}{*}{$\begin{array}{l}\text { 1-RHU max temp } \\
\text { 2-RHU min temp } \\
\text { 3-helium production }\end{array}$} & \multirow{2}{*}{$\begin{array}{l}\text { 1-not over } 500{ }^{\circ} \mathrm{C} \\
\text { 2-not under } \\
\text { 3-heat source containment tolerates helium } \\
\text { compatibility and pressure }\end{array}$} \\
\hline & Heat to heat engine & & \\
\hline \multirow{2}{*}{ Engine } & $\begin{array}{l}\text { Heat available (hot } \\
\text { end temperature) }\end{array}$ & \multirow{2}{*}{$\begin{array}{l}\text { 1-configuration } \\
\text { 2-temperatures } \\
\text { 3-efficiency } \\
\text { 4-freq, amplitude }\end{array}$} & \multirow{2}{*}{$\begin{array}{l}\text { 1-lowest risk configuration selected } \\
\text { 2-cold }=50^{\circ} \mathrm{C} \text {, hot }=325^{\circ} \mathrm{C} \\
\text { 3-target }=20 \% \\
\text { 3-tune to desired convertor dynamics }\end{array}$} \\
\hline & PV power to piston & & \\
\hline \multirow{2}{*}{ Alternator } & Shaft power & \multirow{2}{*}{$\begin{array}{l}\text { 1-inductance, resistance } \\
\text { 2-voltage, current } \\
\text { 3-spring, mass, frequency } \\
\text { 4-size, shape } \\
\text { 5-controller compatibility }\end{array}$} & \multirow{2}{*}{$\begin{array}{l}\text { 1-low inductance alternator being tested, } \\
\text { 2-voltage and current in phase } \\
\text { 3-tune for desired natural frequency } \\
\text { 4-minimize integration challenges } \\
\text { 5-compatible with passive stype controller }\end{array}$} \\
\hline & Stability & & \\
\hline \multirow{2}{*}{$\begin{array}{l}\text { Controller } \\
\text { (1-We output) }\end{array}$} & $\begin{array}{l}\text { AC-DC conversion, } \\
\text { Conditioning }\end{array}$ & \multirow{2}{*}{$\begin{array}{l}\text { 1-efficiency } \\
\text { 2-stability } \\
\text { 3-battery life }\end{array}$} & \multirow{2}{*}{$\begin{array}{l}\text { 1-minimum losses, maximum power factor } \\
\text { 2-amplitude stability at maximum heat input } \\
\text { 3-power management }\end{array}$} \\
\hline & Charge battery, shunt & & \\
\hline \multirow{2}{*}{ Power Bus } & User loads & \multirow{2}{*}{$\begin{array}{l}\text { 1-duty cycling for higher } \\
\text { power needs } \\
\text { 2-continous for lower } \\
\text { power needs }\end{array}$} & \multirow{2}{*}{$\begin{array}{l}\text { 1-batteries are sized for power needs, } \\
\text { momentary burst and low constant usage }\end{array}$} \\
\hline & Sensors & & \\
\hline
\end{tabular}

\section{A. Spacecraft}

Because this is a notional system being considered in early research, not much can be said about how a power system might be mounted or what the thermal interfaces might look like. However, identifying notional temperature boundary conditions will help identify any limitations early in the process. To simply the initial effort, only deep space and Mars surface environmental temperatures were considered. No structural aspects have been considered thus far but will be included in the future as the design matures.

\section{B. Insulation}

American Institute of Aeronautics and Astronautics 
Initial analysis was performed to determine if microporous insulation could be considered for this low power application. The model was setup to only consider heat losses to the insulation package, neglecting all other loss mechanisms. The results showed that if only microporous insulation were used, the hot end temperature would be far below the target of $325^{\circ} \mathrm{C}$ due to heat absorbed by the insulation itself. More efficient insulation is necessary to ensure the convertor hot end temperature is sufficient, like multi-layer insulation (MLI) using low emissivity foils and optically transparent separation materials. Past research efforts had provided some experience in design, fabrication, and testing an MLI package. ${ }^{3}$ A 25 layer MLI package was fabricated for use on an 80-watt ASC from thin layers of low emissivity stainless steel, separated by layers of quartz cloth used to prevent direct contact between the metallic radiation shields. Testing was performed in a vacuum environment using a simulated convertor, where the hot-end temperature of a Stirling thermal simulator was varied from 350 to $750{ }^{\circ} \mathrm{C}$. There were many lessons learned from that test. The insulation was not as efficient as predicted due to an unanticipated increase in emissivity of some stainless-steel foils caused by sublimation of nickel oxide from other test components. Further, the foil layers were difficult to model due to non-uniform packing factor experienced at the closed end of the can shape. Future MLI packages should consider manufacturability and modeling aspects, material compatibility, and integration of radioisotope heat source during fueling.

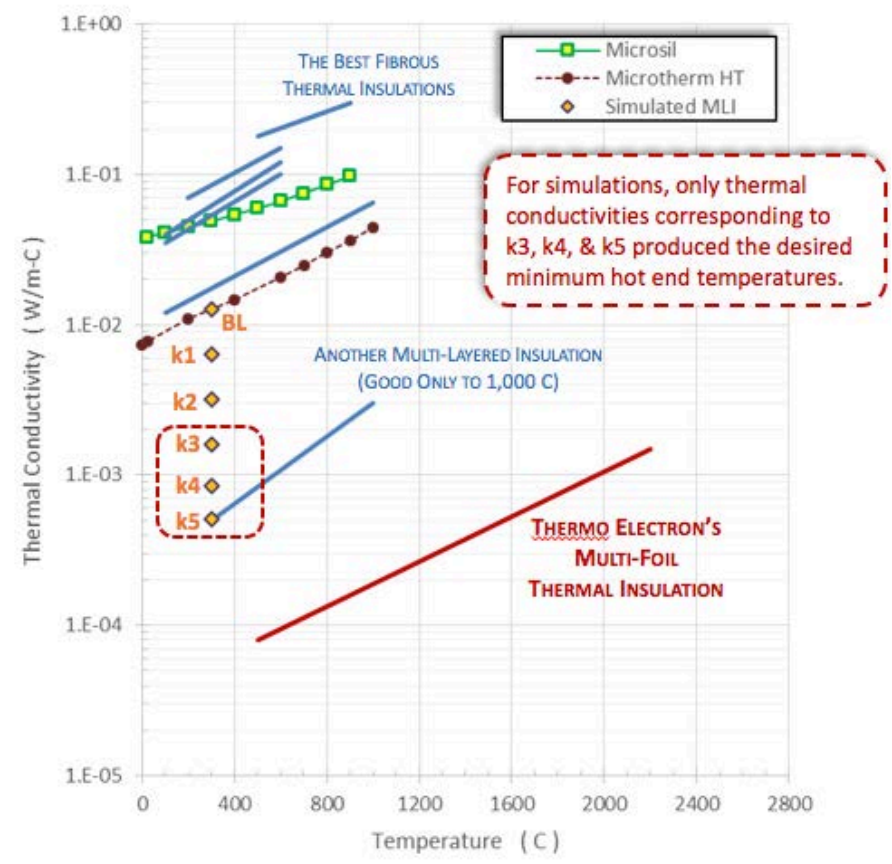

Figure 1. Thermal Conductivity for Various Insulation.

Recent analysis of the low power insulation package was used to determine that the desired effective thermal conductivity is around $0.001 \mathrm{~W} / \mathrm{m}-\mathrm{K}$. This was compared to other MLI packages in Figure 1 and some microporous insulation packages, suggesting this MLI package needs to be somewhere between average and excellent, as depicted by k3, k4, and k5. ${ }^{4}$ Thermal analysis was performed to assess a potential configuration that could be tested to validate a new MLI package. The model consisted of a heat source, simulating the 8x RHUs, a conductive rod to simulate the Stirling cycle. Table II shows boundary conditions which held gross heat addition, effective thermal conductivity, and outer diameter constant while the environmental temperature was varied.

Table II. Boundary Conditions for Simulation of Insulation Package.

\begin{tabular}{|c|c|c|c|c|c|c|c|c|c|}
\hline \multirow[b]{2}{*}{ CASE } & \multicolumn{4}{|c|}{ SET } & \multicolumn{5}{|c|}{ SOLVE } \\
\hline & $\begin{array}{c}\text { ENV TEMP } \\
{ }^{\circ} \mathrm{C} \\
\end{array}$ & $\begin{array}{c}\text { keff } \\
W / m-C \\
\end{array}$ & $\begin{array}{c}\text { PACKAGE } \\
\text { DIAMETER } \\
\mathrm{mm} \\
\end{array}$ & $\begin{array}{c}\text { COLD END } \\
\text { TEMP } \\
{ }^{\circ} \mathrm{C} \\
\end{array}$ & $\begin{array}{c}\text { AVG HOT END } \\
\text { TEMP } \\
{ }^{\circ} \mathrm{C} \\
\end{array}$ & $\begin{array}{c}\text { MAX RHU } \\
\text { SURF TEMP } \\
{ }^{\circ} \mathrm{C} \\
\end{array}$ & $\begin{array}{l}\text { INSUL LOSS } \\
\qquad W_{\text {th }}\end{array}$ & $\begin{array}{c}\text { ROD HEAT } \\
W_{\text {th }} \\
\end{array}$ & $\begin{array}{c}\Delta \mathbf{T}=\mathbf{T}_{\mathrm{HE}}-\mathbf{T}_{\mathrm{CE}} \\
{ }^{\circ} \mathrm{C} \\
\end{array}$ \\
\hline 1 & -270 & 0.0015 & 100 & -108 & 370.0 & 371.0 & -1.62 & -6.38 & 478.0 \\
\hline 2 & -190 & 0.0015 & 100 & -95 & 380.0 & 381.0 & -1.48 & -6.52 & 475.0 \\
\hline 3 & -110 & 0.0015 & 100 & -66 & 396.0 & 397.0 & -1.34 & -6.66 & 462.0 \\
\hline 4 & -30 & 0.0015 & 100 & -21 & 419.3 & 420.4 & -1.21 & -6.79 & 440.3 \\
\hline 5 & 50 & 0.0015 & 100 & 58 & 460.0 & 461.1 & -1.15 & -6.85 & 402.0 \\
\hline
\end{tabular}

Figure 2 shows the model geometry, including the MLI region that was simulated using an effective thermal conductivity, the heat source containing 8x RHU heat sources, and microporous insulation using temperature dependent thermal conductivity. Figure 2 also shows results from Case 5. Of the 8 watts of gross heat input, 1.15 watts was lost to the environment and the remaining 6.85 watts was conducted down the rod to the cold end temperature of $58 \mathrm{C}$. The rod heat transfer closely matches what is required by the engine in order to operate at nominal conditions. 
Performing an insulation verification test using a conductive rod enables hand calculations and less complicated thermal analysis that can quickly help guide design decisions.

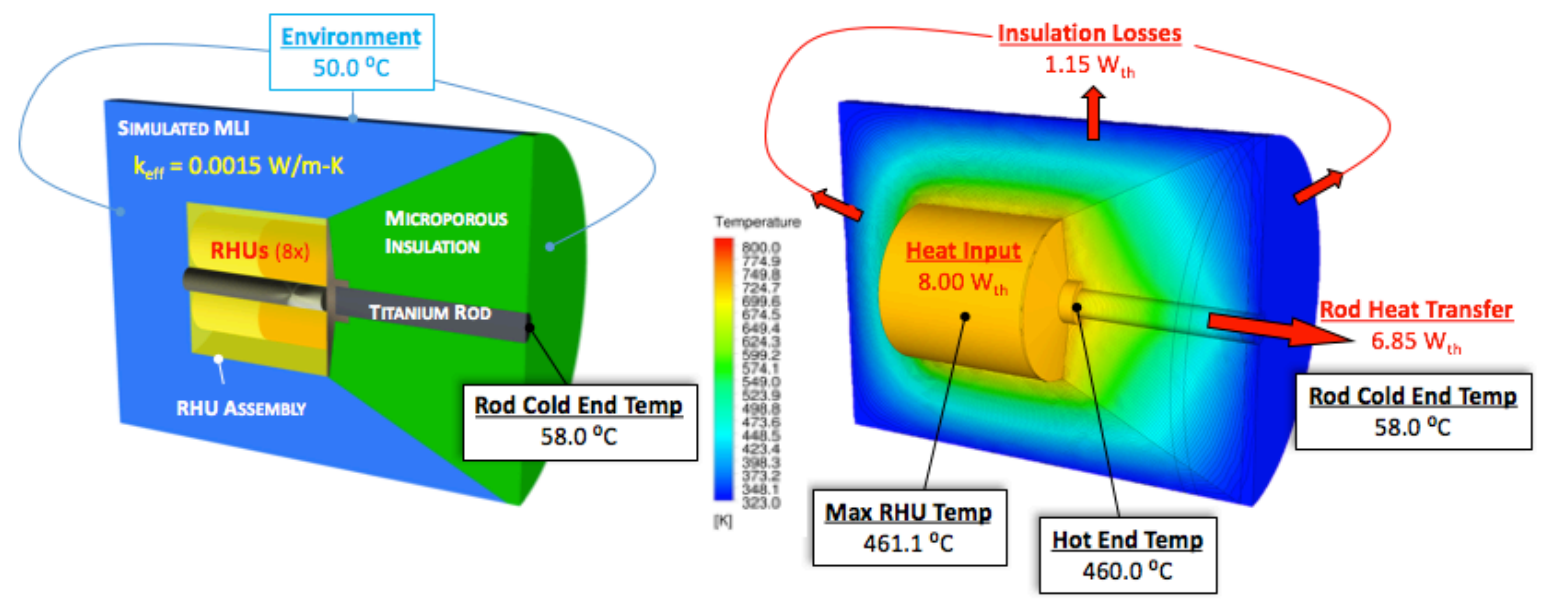

Figure 2. Simulated Insulation Package containing combination of MLI and Microporous Insulation. Model definition (left) and results for Case 5 (right).

\section{Heat Source}

Developed and fabricated by the DOE, RHUs have been used for decades on NASA spacecraft to provide localized heating to spacecraft. RHUs use Pu-238 as the primary source of their energy, decay via alpha emission and have a $1 / 2$ life of approximately 90 years. Because the Pu-238 fuel is hazardous, most of the components surrounding the fuel ensure that the fuel will not be released from the RHU structure to the environment during an accident. The first RHUs were called Mariner Jupiter Saturn (MJS) RHUs and were flown on Pioneer 10 (launched in 1972) and 11, as well as Voyager 1 and 2. The MJS RHUs used on Pioneer 10 and 11 included a single 1-watt RHU and five (5x) 2-watt RHU's. ${ }^{5}$ The 1-watt MJS RHUs were $22.1 \mathrm{~mm}$ in diameter and $47 \mathrm{~mm}$ long with a mass of 57 grams. ${ }^{6}$ Following their successful use on the Pioneer and Voyager missions, it was decided to develop a new, higher power density RHU called the Light Weight Radioisotope Heater Unit (LWRHU). The LWRHH is required to produce 1.1 watts of heat at fueling and weigh 40 grams. Each RHU is $2.6 \mathrm{~cm}$ in diameter and $3.2 \mathrm{~cm}$ in height. Originally scheduled for use on Galileo (GLL) and Solar/Polar missions the design development testing and production required that they be developed in 14 months, however, mission related delays allowed more iterations and resulted in greater safety margins. The first use of the LWRHU was on the Galileo spacecraft launched in 1989 which arrived at Jupiter 1995.

While GPHS use similar materials to RHUs their implementation and requirements are quite different. The GPHS were designed to operate at high temperatures for power conversion while the RHU's were originally designed to keep electrical and mechanical components warm enough to operate effectively. The heat flux coming from the surface of a RHU $\left(36.5 \mathrm{~cm}^{2}\right)$ is approximately 274 $\mathrm{W} / \mathrm{m}^{2}$ while the heat flux from a GPHS $\left(224 \mathrm{~cm}^{2}\right)$ is greater than $11 \mathrm{~kW} / \mathrm{m}^{2}$. These dramatic differences in heat generation per surface area lead to insulation challenges in getting the RHU hot enough to be effective in a power conversion application. Any insulation verification test would use electrically heated heat source to mimic the assumed local thermal profile as if it contained RHUs.

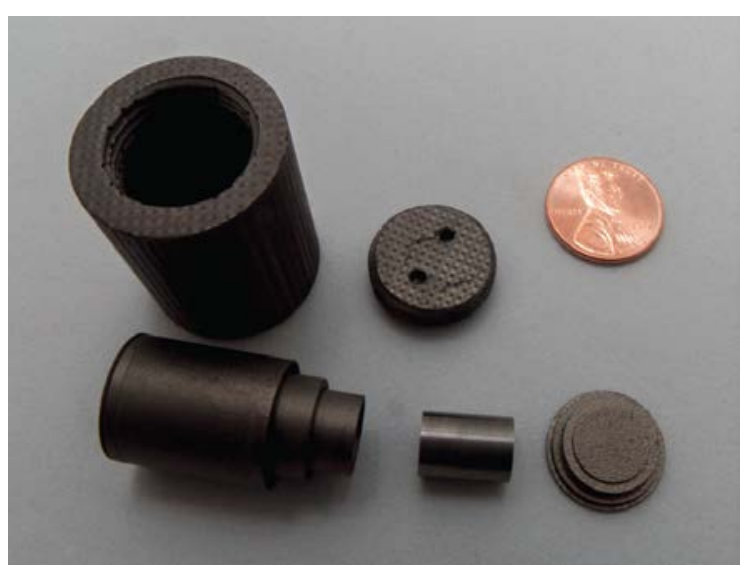

Figure 3. Radioisotope Heater Unit (RHU). 


\section{Engine}

While the fundamental design and evaluation tools employed in the development of free piston and linear alternator Stirling cycle convertors are not specifically limited in the output power range to which they can be applied, the clear majority of the hardware designs in which they have been utilized are with output power levels well in excess of 10 $\mathrm{W}$. This has led to the evolution of a considerable number of "rules of thumb" widely and successfully employed in the design and development of convertors. However, in reality as the power levels fall well below the $10 \mathrm{~W}$ range, for example on the order of $1 \mathrm{~W}$, many of these "rules" cease to be valid. This effect represents one of the key issues in the effective development of low power devices since items that are normally considered minor $2^{\text {nd }}$ and $3^{\text {rd }}$ order effect can represent significant design challenges and constraints.

The following represents key items involving the development of $1 \mathrm{~W}$ class convertors which have been addressed in the current development effort. Note that this listing is primarily focused on the convertor itself and many other items must also be addressed which involve the development on the overall $1 \mathrm{~W}$ power system.

- Cycle configuration - impact on performance \& modeling

- Mechanical integration of components - again impact on performance \& modeling

- Hot end interface with heat source

- Cycle waste heat rejections

- Parasitic heat losses - for example conduction related losses

- Parasitic "mechanical" losses such as seal leakage

- Component physical manufacturing constraints

- Component assembly constraints impacting seals, heat exchangers, bearings, etc.

- Linear alternators

This development effort assessed eight different configurations by assessing them against numerous aspects that could increase developmental risks for successful demonstration and maturation. Figure 4 shows the different configurations and the aspects are listed below. The configuration aspects were individually ranked based on team experience and physical attributes of the configuration that would lend itself to criticism or risk. Those configuration aspects were a) reliability, durability, understanding of failure modes, b) compatible with alternator, c) understood thermal integration, d) flexible packaging and integration, e) mature modeling tools, f) high thermodynamic efficiency, g) low mass and/or volume, h) established manufacturing, i) low technical challenges, and k) low transmitted force.

Examples that would be considered higher risk are low maturity of modeling tools for diaphragm pistons, high transmitted force due to phasing of moving components of the double acting arrangements, and thermal losses for arrangements with lower thermal efficiency. The split Stirling configuration was ranked as the lowest risk option so it was selected for development. this configuration could also be modified to a dual piston arrangement, if desired. A detailed design of the engine was performed in concert with the design of the alternator. The minimum heat input and resulting hot end temperature were assumptions that must still be tested using the insulation test arrangement discussed previously. Several goals were used to guide decisions during the design process. The target electrical power output from the controller is $1 \mathrm{We}$ and the engine had to compatible with any new linear alternator concepts. There was also an attempt made to minimize or eliminate understood critical failure mechanisms.

The engine and alternator design parameters, shown in Figure 5, include a relatively low mean charge pressure of 7.5 Bar, a low hot-end temperature of $350{ }^{\circ} \mathrm{C}$, and an operating frequency of $100 \mathrm{~Hz}$. Using a linear model for the alternator, the convertor efficiency is near $20 \%$ while providing just over 1.3 watts. The low inductance linear alternator will need to be modeled more thoroughly after test data is acquired from the 1 -watt prototype. Figure 5 also 
shows the CAD image of the engine and low inductance linear alternator. The alternator size is relatively large compared to a moving coil alternator that is also being designed as an alternative to the low inductance version.
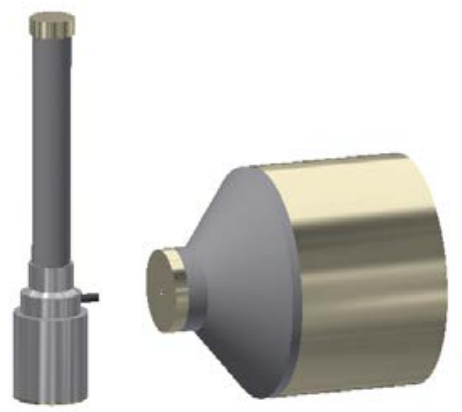

\begin{tabular}{|l|l|}
\hline \multicolumn{1}{|c|}{ Parameter } & \multicolumn{1}{c|}{ Target } \\
\hline Electrical output (W) & 1.33 \\
\hline Thermal input Qin (W) & 6.82 \\
\hline Convertor efficiency & .195 \\
\hline Alternator efficiency & .892 \\
\hline Ta $\left({ }^{\circ} \mathbf{C}\right)$ & 350 \\
\hline $\operatorname{Tr}\left({ }^{\circ} \mathbf{C}\right)$ & 50 \\
\hline Frequency (Hz) & 100 \\
\hline Mean pressure (Bar) & 7.59 \\
\hline Displacer amplitude (mm) & 2.0 \\
\hline Pressure amplitude (bar) & .9 \\
\hline
\end{tabular}

Figure 5. Preliminary 1-watt engine and low inductance linear alternator (LILA).

One critical component that was traded was the regenerator design. A sintered-fiber regenerator was used as the baseline design for early Sage analysis. A gap regenerator was then used in place of the baseline, to determine resulting engine parameters and resulting dynamics. The net effect was a decrease in mean charge pressure and an increase in length and diameter of the displacer to enable sufficient heat transfer area. The detailed mechanical design has begun on the engine and alternator designs and fabrication will start later this summer.

Concurrently with the design challenges mentioned previously, there has also been the advent of innovative analytical tools such as highly integrated multi-physics software and manufacturing methods like 3D additive manufacturing (AM) which open unique opportunities to address many of the noted challenges. There is an effort being made to assess how new manufacturing capabilities can be used to eliminate part count and speed up the manufacturing process. Additive manufacturing has been used to assess some simple shapes that would apply to convertor parts. Those shapes include concentric cylinders held together using tangential connection braces and long thin cylindrical parts with flat ends and thin walled cones printed inside the cylinder. The concentric cylinder shapes could represent printed foil regenerators that could be installed separately into a convertor or printed directly to other parts, like heat exchangers and external pressure boundaries. The thinnest wall that has been printed so far using Inconel 718 powder is 55 microns. An assessment of porosity is planned to understand the structural integrity and potential impacts on thermal performance. Additionally, 100 micron thick walls were printed more reliably and appear to be sufficient to entertain manufacture of foil regenerators for Stirling convertors. While In718 was used more for convenience, other high temperature materials are available for AM. Figure 6 shows the end view (left) and the cross section after cutting in half (right) of the concentric cylinder part. The presence of melted powder material, considered a defect, will be remedied with further optimization of the machine build parameters. In addition to foil shapes, there has been an attempt to print a displacer shape, containing a closed end, internal baffles, and an attached displacer rod. The trial is still in process but initial results suggest that the two parts, one 100 micron thick walls and one 300 micron thick walls, printed in In718 has successfully been printed.
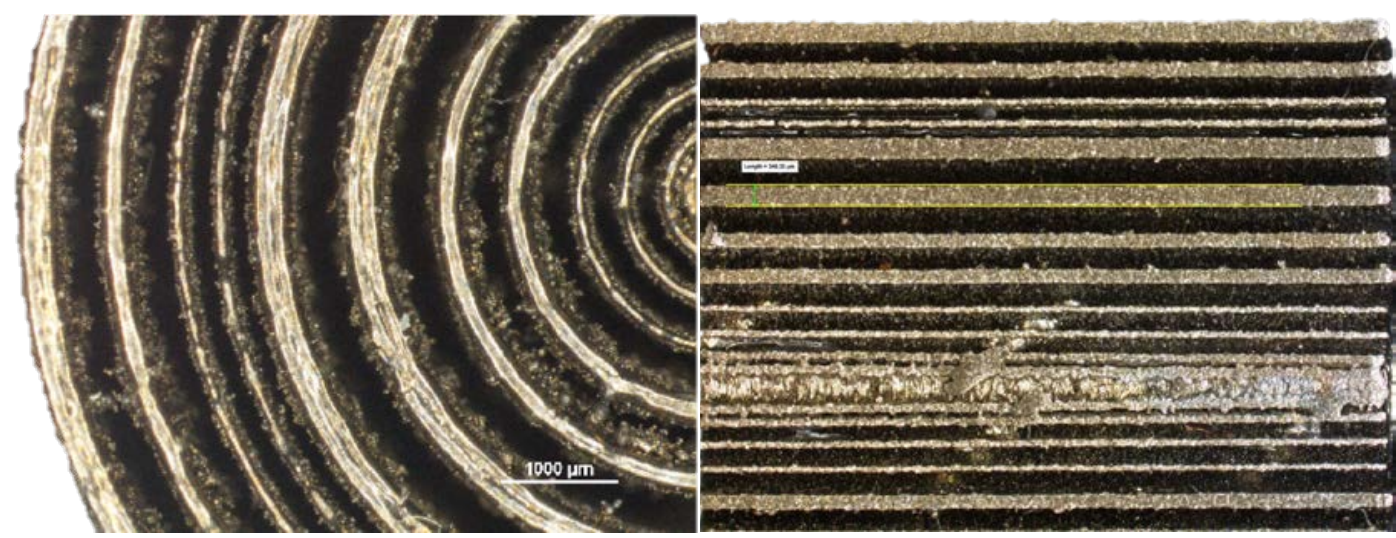

Figure 6. Concentric cylinder trials using additive manufacturing.

American Institute of Aeronautics and Astronautics 


\section{E. Flexure Bearing Design}

Piston and displacer flexure bearings are being designed for the 1-watt convertor. Ideally, the flexure outer diameter would be as small as possible, but this dimension is often limited by the desired amplitude of deflection, which is generally $10-15 \%$ of the active flexure diameter. This rule of thumb was followed in setting the diameter constraints for this design. The operating frequencies were a direct result of a SAGE analysis. For the initial spring test, a factor of safety of $10 \%$ over the engine design amplitude was employed. The axial stiffness was calculated based the estimated moving mass and operating frequency. The radial stiffness was more of a goal than a requirement and was calculated as the stiffness required to deflect 10 microns under a constant $20 \mathrm{~g}$ side load for the estimated mass. The spring torsional stiffness is required to resist a small torque applied by this particular alternator's design, which imparts a small oscillating magnetic side load.

These flexures are being design and analyzed using COMSOL. In COMSOL, the flexures are independently axially, radially, and angularly deflected. The stiffness for each type of deflection is calculated based on the force or torque required and amount of deflection. The maximum Von Mises stress is monitored in each case, and the flexure is being designed to have a maximum stress level that is less than the modified Goodman fatigue stress value for the material of interest. A modal analysis of the flexure is also being completed. The challenge in flexure design is to converge on a single design that meets each of these requirements. Once design of these flexures is complete, fabrication and testing will be pursued to enable model verification. A test rig is being prepared to subject the springs to operation near $100 \mathrm{~Hz}$ operational frequency. The test rig, shown in figure 7 , will be able to vary the operational frequency, number of springs on test between 1 and 6 , and amplitude of oscillation.

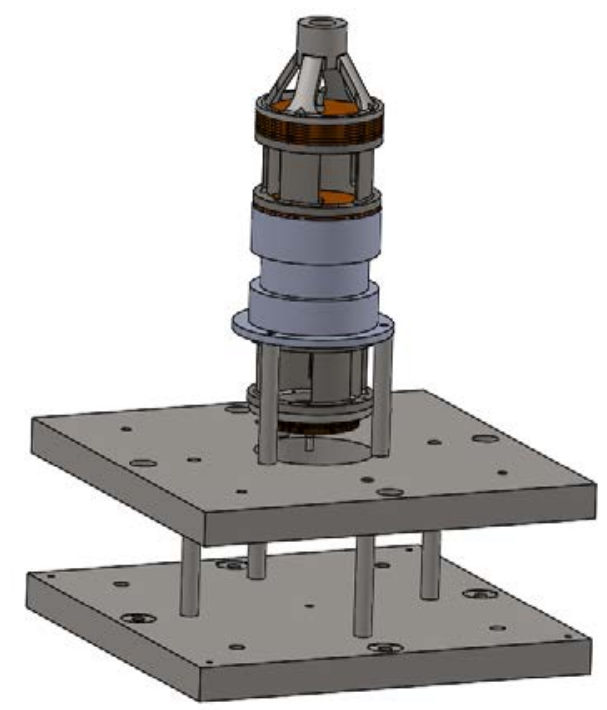

Figure 7. Flexure Evaluation Test Rig.

\section{F. Alternator}

As a potential alternative to a traditional moving coil alternator design, a new type of alternator is being developed at GRC. This new concept utilizes a dual-Halbach array of magnets and moving coil to convert linear shaft power into electricity. ${ }^{7}$ The coil is supported by flexural bearings, which are also used to conduct the induced current from the coil to the terminals. A key feature of this new concept is the ultralow inductance, which could eliminate the need for power factor correction and associated physical or digital tuning capacitors required by the controller. A proof-of-concept demonstration was prepared and has been operated at full mover design amplitude of 5.5 millimeters. The measured power output was 7.5 watts when connected to a $5 \mathrm{Ohm}$ load, which is within 4 percent of the model prediction of 7.8 watts. The measured power factor was 0.995, successfully demonstrating the desired low inductance. The test rig was designed to vary a number of parameters including number of magnets, number of coils, coil diameter, stator running clearance, amplitude, and frequency. Figure 8 shows that the measured voltage and current values are in phase. Higher power density is expected as the design is refined and the modeling results indicate that the addition of a small amount of iron positioned in the center of the coil can greatly increase the power output with negligible impact on inductance.

Next steps include fabrication of scaled down 1-watt units and assessing the technology for higher power radioisotope power system applications. As previously mentioned, a moving coil linear alternator is also being investigated to ensure there is traditional alternative. The test rig is also fitted with two linearly adjustable plates that

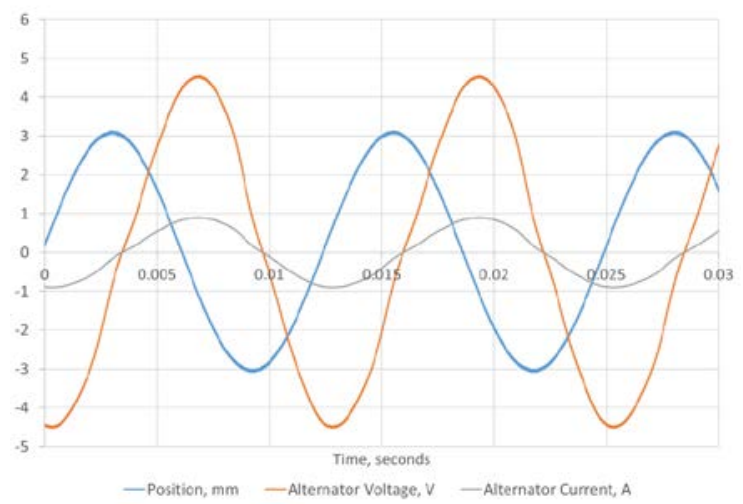

Figure 8. Test data from Low Inductance Linear Alternator test rig. Voltage and current are in phase, resulting $P F=0.995$.

slide along four guide rails to enable adjustability of the magnet spacing. Each plate's location can be independently and precisely adjusted using a threaded knob and locked into place using set screws. A magnet holder containing a 
clamping fixture is bolted to each plate, and customized magnet holders can be fabricated if needed for vastly different designs. This test rig was designed to allow adjustability of each alternator component, and to enable alternator performance sensitivity mapping. For this reason, the test rig is bulky in comparison to what optimized alternator packaging could be.

The alternator design for the 1-watt convertor is being performed using inputs from the engine design and providing outputs to the controller design. The primary engine input parameters include frequency and amplitude. The current design, the upper set of four magnets guides the magnetic flux in a counter-clockwise direction while the lower set of magnets guides the magnetic flux in a clockwise direction. There are four coils wired in series that translate vertically between the air gaps of the adjacent magnet poles. As the coils move from one end of stroke to the other, the magnetic flux cutting the coils completely reverses. The coils would need to be carried in a mover structure and the mover constrained by stacks of flexure bearings. The flexures also serve as a conduction path for the current induced in the coils. Figure 9 shows this configuration, with iron positioned inside the coil windings to bridge the air gap between the adjacent magnet poles and improve performance. This design is being prepared for testing, where test measurements will be made and compared back to the prediction code.

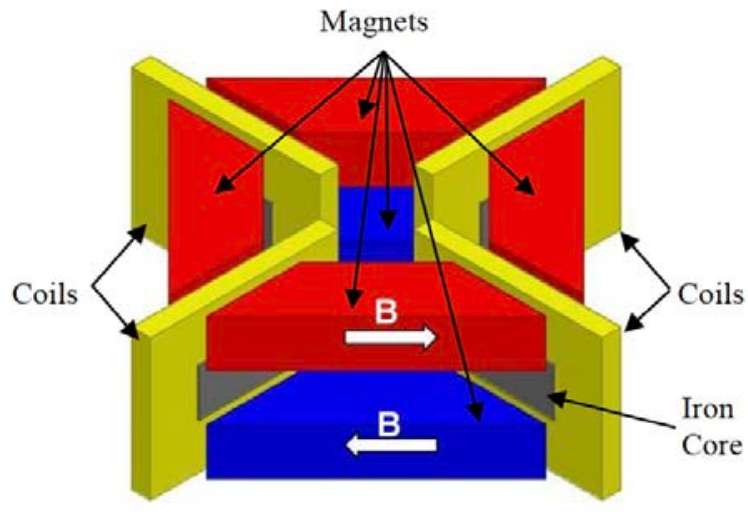

Figure 9. 1-watt low inductance linear alternator design.

\section{G. Controller}

Due to the very low power of the 1-watt Stirling convertor, a passive controller was selected to minimize complexity and losses. An analog controller is being designed to control the convertor and provide DC power for a battery charger and load control system. The basic functionality includes providing a load for stability, AC-DC conversion, wave form smoothing, battery charging, and the ability to shunt excess electrical power when the battery is full. Initial operational concept is for the controller to charge a battery for a period of time and then switch on the loads for collection of data and transmission of telemetry. This cycle of battery charging and telemetry transmission will then be repeated allowing the low power Stirling engine to power higher power electronics on a periodic basis. The load control portion of the controller will include a shunt circuit to dissipate excess converter power not required by the battery charger or the load. This would be the case as the battery is nearing full charge or when the system loads might be turned off for longer periods of time. The shunt is being designed to dissipate partial of full engine power to keep engine operating at constant power levels.

Initial modeling of the analog controller using a representative electrical model of the linear alternator design has been performed using LTspice from Linear Technology. The first stage of the analog controller is a standard diode bridge for rectifying the AC voltage along with a DC cap to smooth the voltage and provide a DC voltage to the loads. The modeling results show that a tuning capacitor is not required due to the low power levels. Although the inductor current remains in phase with the inductor voltage without the tuning capacitor, the model shows that the conversion from AC to DC creates a Total Harmonic Distortion (THD) over 50\%. This THD level results in lower available power from the Stirling engine. Passive filters were included in the model in an attempt to lower the THD below $10 \%$. The modeling results show that the resistance levels of available inductor and capacitor components required for the filters, lowers the efficiency of the controller to roughly $70 \%$. Future controller developments will consider the use of active designs to improve the THD as part of the load voltage conversion. Modeling of the battery charger and load control circuits has begun but have not been completed yet.

Figure 10 shows initial modeling results of the inductor voltage and current as well as the output voltage and current of the rectifier stage. Current results show the controller provides approximately $1 \mathrm{~W}$ continuously to the battery charger. 


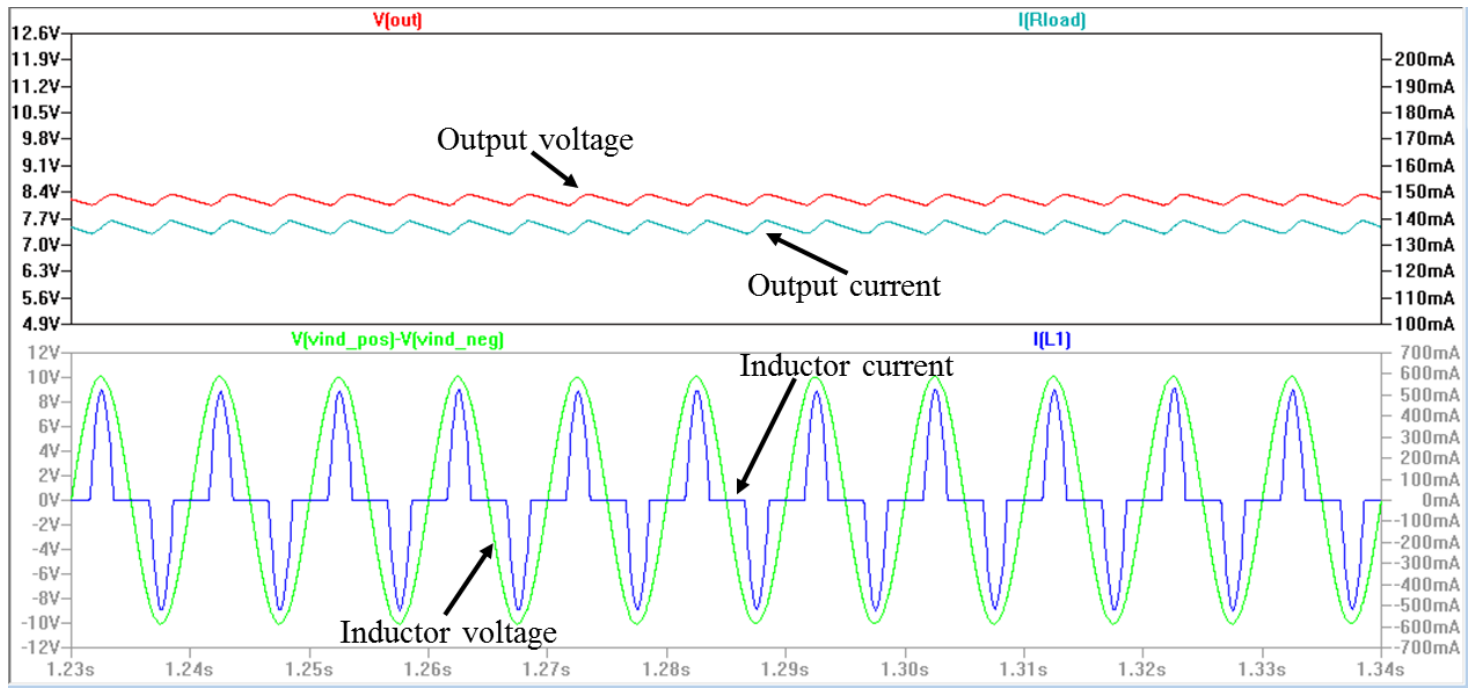

Figure 10. Initial modeling results for rectifier stage of analog controller.

\section{H. Spacecraft - User Load}

Instruments required for surface observation stations could include measurements of pressure, temperature, seismic data, acceleration, wind, and optical data. The power required to operate one of the potential instruments used to collect science data or communicate data to a satellite may exceed the total available power. Therefore, an initial controller design will include a battery charger for demonstration purposes. Some simulated sensors are planned for addition to the controller model. The controller modeling effort will consider one simulated instrument that exceeds the power level like an antenna, at several watts of temporary power usage, and a few lower power instruments that do not exceed the available power, such as a force-feedback seismometer at $150 \mathrm{mWe}$ or a hot-film anemometer wind sensor at 250-380 mWe. The modeling effort is expected to complete later this year.

\section{Conclusion}

The RPS Program Office is working in collaboration with the U.S. Department of Energy (DOE) to develop RPS systems for space science missions. The Stirling Cycle Technology Development (SCTD) Project is developing Stirling conversion technologies, such as convertors, controllers, and supporting technologies that focus on a wide variety of objectives. A 1-watt Stirling convertor is being developed at NASA GRC to provide flexible options for future micro spacecraft. Initial concepts convert heat available from eight RHUs to 1-watt of electrical power for spacecraft instruments and communication. Development activity includes defining and evaluating a variety of Stirling configurations, validating analysis using component tests, completing detailed design of engine and alternator, validating potential insulation designs, and investigating advanced manufacturing methods that could simplify fabrication and decrease costs. The test hardware is being prepared for an upcoming demonstration in a laboratory environment.

American Institute of Aeronautics and Astronautics 


\section{Acknowledgments}

This work is funded through the NASA Science Mission Directorate and the Radioisotope Power Systems Program Office. The authors wish to acknowledge Nick Schifer, Terry Reid, Randy Bowman, and Mike Casciani for their contributions to the Mini Stirling development effort. Any opinions, findings, conclusions, or recommendations expressed in this article are those of the authors and do not necessarily reflect the views of NASA.

\section{References}

${ }^{1}$ NASA Office of Space Science, “Enabling Exploration with Small Radioisotope Power Systems”, JPL Pub 04-10, September 2004.

${ }^{2}$ Lorenze, R. et al., ”MASER: A Mars Meteorology and Seismology MiniNetwork Mission Concept Enabled by MilliwattRPS”, 2014 IEEE, 978-1-4799-1622-1114

${ }^{3}$ Wilson, S.D., Schifer, N.A., Williams, Z.D., Metscher, J.F., “Overview of Stirling Technology Research at NASA Glenn Research Center”, NASA/TM-2016-218909.

${ }^{4}$ TE420910076, "Preliminary Design Review Document Application of Multi-Foil Insulation to the Brayton Isotope Power System and Conceptual Design of Multi-Foil insulation for the Flight System (Phase I)”, For the U.S. Department of Commerce, National Technical Information Service, THERMO Electron CORP., Waltham, Mass, June 1976.

${ }^{5}$ National Aeronautics and Space Administration Environmental Statement for Mariner Jupiter/Saturn Project, June 1973 NASA-741756-D.

${ }^{6}$ R.E. Tate, The Light Weight Radioisotope Heater Unit (LWRHU): A Technical Description of the Reference Design., January 1982 LA-9078-MS

${ }^{7}$ Geng, S.M., Schifer, N.A., “Development of a Low Inductance Linear Alternator for Stirling Power Convertors”, Proceedings of the Fifteenth International Energy Conversion Engineering Conference, AIAA, Atlanta, GA, 2017.

American Institute of Aeronautics and Astronautics 